\title{
Tendencias recientes en la política mundial
}

\begin{abstract}
Jose Agustín Silva MIGHELENA, Cientīsta politico venezolano, es investigador del Centro de Estudios del Desarrollo (CENDES) de la Universidad Central de Caracas. Autor, junto con Frank Bonilla de Strategy for Research on Social Policy: The politics of changes in Tenezuela $\mathrm{y}$ de Crisis de la. Democracia, viene trabajando desde hace años en un proyecte encaminado a identificar modelos alternativos de desarrollo para su pais, señalando los costos sociales de las diferentes opciones, proyecto del cual forman parte las dos obras mencionadas.
\end{abstract}

\section{INTRODUCCIÓN}

El presente trabajo tiene el carácter de informe sobre el progreso de una investigación. Se trata pues, de un conjunto de hipótesis que están en vías de verificación. En este sentido debemos advertir al lector que algunos aspectos de la investigación tienen un mayor grado de fundamentación que otros y que, en general, se trata de un primer esfuerzo de síntesis de variadas formulaciones sobre un tema, cuya vastedad y complejiclad es lo único bien establecido en el campo de las ciencias sociales.

El objetivo general de la investigación es el de" examinar las características del deșarrollo de América Latina a la luz de su progresiva inserción en el sistema capitalista mundial. El examen de este proceso socio-histórico debe permitimos delinear las probables alternativas de desarrollo de América Latina ${ }^{1}$. Si bien el aspecto principal de la investigación debe centrarse en el estudio del desarrollo de la progresiva implantación de las formaciones sociales latinoamericanas, partimos de la premisa que el marco dentro del cual se realizarán las alternativas de desarrollo posibles, viene sobredeterminado por las actuaciones de loṣ grandes bloques de poder a niyel mundial.

*El presente trabajo resume los resultados de las investigaciones de un equipo integrado además por los siguientes investigadores: Alvaro Agudo, Luisa Camacho, Gastón Carvallo, Elena Díaz y Carmen Elena Parés. Tratándose del primer avance de un proyecto recién iniciado se agradecen los comentarios de los lectores interesados.

"Sub-equipo II. "Proceso Socio-histórico de América Latina"; Proyecto Desarro$1 l$ y y Dependencia de América Latina; CONICIT DF-SP-080 y UCV. (Caracas: Mimeografiado, Julio de 1972). 
El primer obstáculo con que se encuentra el investigador al tratar de aproximarse al último aspecto señalado es que las reflexiones so bre la política mundial adolecen de al menos uno de estos dos graves defectos:

(i) Limitar el análisis a las relaciones inter-imperialistas o a las relaciones entre los países imperialistas y los subdesarrollados y (ii) Dejar de tomar en consideración las determinaciones estructurales al considerar la política de los países líderes de los campos socialista y capitalista como resultado de factores inherentes a su condición de "superpotencias". Consideremos, brevemente, cada uno de estos puntos.

Hasta la aparición del campo socialista el análisis de las relaciones internacionales -en el sentido amplio de la palabra - encontraba un marco interpretativo preciso en la teoría del imperialismo. En efecto, desde mediados del siglo pasado la creciente expansión del capitalismo en el mundo ya había unido sus partes más distantes en un sólo movimiento. Adam Smith ya había anotado ese fenómeno, pero fue Marx quien más claramente trazó el sentido histórico de ese movimiento expansivo:

"La tarea específica de la sociedad burguesa es el establecimiento de un mercado mundial, por lo menos en un plan general, y de la producción basada en este mercado. Como la tierra es redonda esto parece haber sido concluido con la colonización de California y Australia, y con la apertura de China y Japón."'2

Si bien las relaciones económicas actuarían como arietes transformadores de las economías "menos progresivas" incorporándolas a un mercado mundial, esta fuerza transformadora no se quedaría allí, sino que gradualmente iría transformando también el resto de esas sociedades, de modo que la interdependencia universal de naciones pronto abarcaría todos los campos de la actividad humana:

"En lugar del viejo aislamiento local y nacional, de la autosuficiencia, tenemos intercambio en todas las direcciones, interdependencia universal de naciones. Tanto en lo material como en la producción intelectual. Las creaciones intelectuales de naciones individuales se convierten en propiedad común."3

Se comprenderá entonces que cuando Lenin, casi medio siglo

"Avinieri, Shlomo Ed. Karl Marx on Colonialism and Modernization Fis dispatches and other writings on China, India, The Middle East and North Africa. (New York: Anchor Books, 1969) p. 464.

IIbidem (p. 36). 
después, formula la teoría del imperialismo como fase superior del capitalismo, lo haga en términos que abarcan a todo el mundo, puesto que ya el proceso de unificación estaba mucho más avanzado.

Las varias contribuciones que se han hecho posteriormente en torno a la teoría del imperialismo, casi todas encaminadas a incluir los nuevos desarrollos del capitalismo, al menos que nosotros sepamos, no han enfrentado adecuadamente el problema de la creciente heterogenización del mundo como consecuencia de la aparición de los países socialistas. Esta omisión exa aceptable hasta la Segunda Guerra Mundial, ya que el aislamiento de la Unión Soviética y su relativamente poco peso específico en la política mundial afectaba muy poco los análisis que se hacían. Sin embargo, a partir de la Segunda Guerra Mundial el campo socialista se expande significativamente, de modo que incide tanto sobre la propia política imperialista como sobre los países subdesarrollados. En consecuencia, el análisis de la política mundial basado en la teoría del imperialismo, cuando ménos resultaba incompleto. Las eventuales consideraciones que se han hecho sobre la forma como la presencia del campo socialista han afectado las relaciones internacionales y adolecen de falta de coherencia teórica. Es decir, esas formulaciones no estaban orgánicamente ligadas a la teoría del imperialismo.

Las formulaciones que pretenden desde una misma perspectiva teórica explicar la política mundial, por lo general adoptan una posición epistemológica inaceptable: ante el aparentemente homogéneo comportamiento de las "superpotencias", olvidan que hay bases económicas estructuralmente diferentes. Algunas de estas formulaciones revelan su claro corte ideológico al extender el término "imperialismo" para calificar también a la política de un país socialista como la Unión Soviética. Otros, un tanto más pragmáticos, se limitan a hacer conjeturas sobre los "intereses comunes" de los países lídexes de los campos capitalista y socialista. Obviamente en éstos análisis se encuentran con bastante frecuencia algunas formulaciones muy penetrantes que describen acertadamente ciertas coyunturas, pero debido a sus falsas premisas de método, jamás pueden ofrecer explicaciones satisfactorias de los fenómenos que analizan.

El problema teórico que se ha planteado en las páginas precedentes, se puede entonces resumir de la siguiente manera: elaborar un conjunto de formulaciones teóricas que, al mismo tiempo que provean una base interpretativa común para el comportamiento de los campos socialista y capitalista, tome también en consideración que se trata de dos campos en los cuales imperan modos de producción diferentes. 
EL CONCEPTO DE GRAN POTENGIA

El problema teórico planteado en las páginas precedentes encuentra una primera vía de solución en las formulaciones de Gramsci que se refieren à las grandes potencias ${ }^{4}$. El concepto es eminentemente político, puesto que su finalidad es la de permitir el estudio de los posibles enfrentamientos bélicos entre los países avanzados; el enfrentamiento es visto como la extrema expresión de los conflictos inter-imperialistas o bien imperialista-socialista. En este último caso, la explicación, en última instancia, de los comportamientos de las grandes potencias vendría dada por la interrelación entre las exigencias propias de ser Gran Potencia y las determinaciones provenientes de la particular formación social involucrada.

En el nivel más general, según Gramsci, una Gran Potencia sería un país que cuenta con todos los elementos necesarios para, en la medida de lo posible, garantizar la victoria en caso de que se produzca un enfrentamiento. $\mathrm{O}$ bien, el país que posea un potencial de presión tal, que le permita obtener, al menos en parte, los resultados de una guera victoriosa sin haber llegado a combatir. Las vias específicas mediante las cuales una gran potencia logra este objetivo general son: (i) creando en su seno las condiciones necesárias para llegar a ser una gran potencia y (ii) tener la capacidad de expresar políticamente el comportamiento de Gran Potencia que esas condiciones permiten. Examinemos un poco más detalladamente ambos puntos.

(i) Según Gramsci, las condiciones necesarias para que un país pueda ser o llegar a ser una Gran Potencia son las siguientes:

1. Extensión territorial suficiente con consideración concreta de su posición geográfica.

2. Fuerza económica, distinguiendo particularmente el nivel de desarrollo de las fuerzas productivas y en particular sus capacidades industrial, agrícola $y^{\prime}$ financiera. Podríamos añadir que en los tiempos actuales es necesario darle especial ponderación a la capacidad tecnológica que se expresa tanto en la capacidad. industrial como en el desarrollo nuclear, coheteria y desarrollo para la exploración y explotación espacial.

3. Fuerza militar, en la que se resumiría el valor de su exten-

¿Véase Antonio Gramsci. Note sul Machiavelli, sulla Politica e sullo Stato Moderno (Roma, Giulio Einaudi, Editore, 1966) 
sión territorial y de su posición geográfica en relación a la población y al yalor del potencial económico.

4. Tranquilidad interna, entendiendo por esto la existencia de un balance positivo a favor de las clases y grupos sociales hegemónicos.

5. Una posición ideológica históricamente determinada que permita ejercer la influencia necesaria para mantener interna y externamente (con sus aliados) un cierto nivel de cohesión.

(ii) La capacidacl para poder expresar políticamente el comportamiento de gran potencia que esas condiciones permiten se pueden resumir en lo siguiente:

1. La capacidad de imprimir a la actividad estatal una dirección efectivamente autónoma.

2. La capacidad de ser cabeza y guía de un sistema de alianzas y de pactos para formar un bloque de poder.

3. La capacidad de mantener una correlación de fuerzas tal, que permita al país en cuestión, hacer que los "aliados" cumplan con las promesas y pactos de la alianza.

4. La capacidad general de influir sobre otros estados que no estén en su zona de influencia.

El comportamiento de gran potencia se expresa entonces en la concreción de las capacidades señaladas; sin embargo, ello no ocurre "por casualidad" o porque los dirigentes de un país determinado sean más hábiles que los de otros, sino que ello es el resultado de desarrollos históricos concretos que determinan que en una cierta época histórica un país se convierta en gxan potencia. Así, la explicación de que Estados Unidos y la Unión Soriética sean hoy en día grandes potencias hay que buscarla en la dinámica del sistema capitalista mundial y en el proceso de formación del bloque socialista respectivamente. Más aún, la formación de estos bloques y su ulterior resquebrajarniento y fisuras hay que examinarlos a la luz de las relaciones específicas entre las clases hegemónicas y sus opositores dialécticos en las grandes potencias y sus zonas de influencia. Así, la formación de un bloque supone que las clases hegemónicas de la gran potencia tienen intereses comunes con las clases hegemónicas de las zonas de influencia. Esta comunidad de intereses, sin embárgo, nunca es total y en ciertas circunstancias pueden llegar a ser contradictorios; lo que explicaría en gran medida las fisuras, rupturas y no alineaciones. Por esta, razón puede decirse que aun cuando en lo político-formal las alianzas y pactos comprometen a las naciones como un todo, en la dinámica real de la historia operan como alianzas y 
pactos de clases hegemónicas y por tanto están sujetas a los cambios que puedan ocurrir como resultado de la lucha de clases que se libra en el interior de cada país, y en general a nivel mundial.

\section{LAS ZONAS DE INFLUENGIA}

Toda Gran Potencia tiende a formar bloques de poder en los cuales ella ejerce un liderazgo económico, politico y militar. El bloque, en la medida en que esté cohesionado, aumenta el poder de la gran potencia frente a otras; pero dentro de un bloque no pueden existir en armonía dos o más grandes potencias ya que los intereses hegemónicos de las clases dominantes de cada gran potencia los haría entrar en conflicto.

Dentro de las zonas de influencia debemos distinguir dos conjuntos de países: (i) aquellos cuyas condiciones (extensión territorial, fuerza económica, fuerza militar, etc.) son tales que si el pais cambiara de una zona de influencia a otra, ocumiría un cambio cualitativo en la correlación de fuerzas entre las grandes potencias que se enfrentan. Estos países constituirían lo que denominamos la zona de equilibrio. (ii) Aquellos países de poca extensión territorial o de gran extensión, pero de economia dependiente, escaso desarrollo tecnológico, débil fuerza militar, bajo nivel de influencia en las decisiones políticas internacionales y aun nacionales, y en los cuales - por sus contradicciones estructurales- se producen tensiones que se convierten, o permanentemente amenazan en convertirse, en luchas armadas intestinas o en guerras de liberación nacional, las denominamos zonas periféricas. En suma, pues, un país periférico es aquel cuyo pase de una zona de influencia a otra no es un elemento capaz de modificar sustantivamente la correlación de fuerzas entre los bloques.

El sistema, de relaciones que se establece en un bloque determinado es jerárquico, en el sentido de que la gran potencia es siempre hegemónica e impone directrices políticas, influye económicamente sobre la zona de equilibrio y domina a las zonas periféricas. Estás últimas, pueden estar también dominadas por países de las zonas de equilibrio quienes algunas veces son los intermediarios entre la potencia y el país periférico.

La existencia de una zona de influencia implica, pues, que los países que la constituyen encuentren sus intereses económicos, politicos y militares de aIguna manera supeditados a, o dependientes de, los intereses económicos, políticos y militares del país centro. Más aún, que el país centro ejerza también un liderazgo ideológico que 
le dé coherencia al bloque. Esta dependencia o supeditación se realiza a través de los intereses específicos de las clases dominantes en cada país y por tanto ella puede ser real, en la medida en que el país centro vaya adquiriendo una importancia estratégica (económica, militar o política) para una Gran Potencia y ésta asuma, en relación a ese país, un comportamiento como tal con miras a incluirlo dentro de su propia zona de influencia.

Igualmente, determinadas circunstancias históricas pueden hacer que un país asuma un comportamiento de Gran Potencia aun cuando no estén maduras todas las condiciones para serlo. En suma, se trata de una situación dinámica que conforma dentro de circunstancias históricas específicas. Pasemos puẹ, a la luz de estos concep-, tos, a examinar la situación actual con miras a sacar algunas conclusiones relevantes con respecto a las posibles alternativas de desarrollo abiertas a los países latinoamericanos.

\section{OBJETIVOS DE LAS GRANDES POTENCIAS}

Las grandes potencias, cualquiera que sea el modo de producción que las caracterice, tienen un objetivo común que es permanente: mantener y expandir sus zonas de influencia, puesto que su poder viene dado por el poder global del bloque.

Si bien los razonamientos que se han hecho anteriormente tiene una validez general, ellos se hacen concretos al considerar el campo capitalista y el campo socialista ${ }^{5}$. Ambos campos han seguido su propio curso de formación e integración en bloques de poder. En el curso de los últimos años han aparecido fisuras y tensiones internas que han modificado substancialmente la bipolaridad del mundo de la post-guerra. Comencemos por caracterizar especificamente los objetivos de ambos campos.

En el caso de las grandes potencias capitalistas, el objetivo general se hace históricamente concreto en los objetivos del imperialismo. Si bien la política de colonización es anterior a la fase imperialista del capitalismo, es durante esta última cuando el capitalismo llega a expresarse plenamente a través de grandes potencias. Obviamente, los objetivos específicos han cambiado junto con los cambios en el panorama capitalista mundial, por lo que habría que distinguir

"El término "campo" lo usamos para referimos a un conjunto de países cuyas relaciones de producción permiten caracterizarlos como constitutivos de un modo de producción específico (ej. capitalista o socialista). Obviamente, dentro de un campo pueden haber dos o más bloques de poder. 
varias fases: (i) fase pre-imperialista, (ii) fase de la Primera Guerra Mundial, y (iii) fase de la Segunda Guerra Mundial.

No intentaremos en este trabajo examinar cada una de estas fases, sino que limitaremos nuestras consideraciones a la última fase.

En la fase posterior a la Segunda Guerra Mundial, los objetivos del imperialismo podrían resumirse en los siguientes enunciados:

a. Asegurarse la provisión de materias primas mediante la apropiación de las fuentes.

b. Garantizar el flujo hacia los mercados mundiales de mércancías manufacturadas.

c. Garantizar el flujo del excedente de capitales.

d. Mantener los mercados mundiales de capitales a través de múltiples vías de inversión incluyendo la inversión directa en manufactura.

e. Control financiero mundial.

A estos objetivos económicos habría que añadir algunos de carácter político:

a. Impedir la expansión del campo socialista.

b. Mantener la unidad de la burguesía en el campo capitalista y la hegemonía de la burguesía de la gran potencia.

En el caso del campo socialista los objetivos concretos han sido menos estudiados en cuanto tales. No existe una teoría comparable a la teoría del imperialismo, que permita precisar los objetivos de política internacional del campo socialista. Nuestras investigaciones, aun cuando todavía están en una fase preliminar, nos llevan a formular la hipótesis de que en el campo socialista los objetivos de carácter económico son instrumentales para el logro de un objetivo político único: la expansión del sistema socialista.

Este objetivo, sin embargo, se ha expresado de diversas formas según sea el período que se considere:

"Esta variabilidad puede ser explicada como consecuencia de un proceso en el que se equilibraban, por una parte, la evolución interna del socialismo en la propia URSS, es decir, la evolución de sus capacidades internas $y$, por la otra, el proceso cambiante de la política mundial". ${ }^{6}$

'Malexi José Pompermayer y Benicio Viero Schmidt, "Relaciones entre la Unión Soviética y América Latina". (Caracas: Mimeografiado, CENDES, 1971) p. 25. 
José A. Silva Ifichelena / Tendencias recientes en la poiltica mundial

Así pueden distinguirse las siguientes fases y sus respectivos objetivos:

1. Fase del "socialismo en un sólo país": dominaba la necesidad de la supervivencia del socialismo frente a las amenazas provenientes del campo capitalista y ante el fracaso de la internacionalización de la revolución. Esta fase llega hasta la Segunda Guerra Mundial.

2. Fase de formación del bloque socialista: en este periodo se plantea como necesidades inherentes al desarrollo de la Guerra Fría la expansión del poder de la URSS mediante la consolidación del bloque socialista.

3. Fase de la coexistencia pacífica: en este período se plantea la expansión del socialismo hacia las zonas periféricas.

De la consideración de los objetivos de los campos capitalista y socialista puede extraerse como conclusión que el campo capitalista tiene un interés primordialmente económico en impedir la expansión socialista, de lo que resulta una necesidad política e ideológica de combatirlo. En el campo socialista, en cambio, hasta muy recientemente el interés primordial en expandirse era de naturaleza política lo que, al menos teóricamente, permitía una mayox flexibilidad en las alternativas; sin embargo, una vez superada la fase en la que la supervivencia y la seguridad del campo corrían peligro inminente, $y$ en la medida en que aumenta la interdependencia económica del campo socialista y en especial de éste con países neutrales o del campo capitalista, surgen necesidades económicas específicas que probablemente modificarían la política exterior socialista. Este aspecto, sin embargo, aún no ha sido abordado por nosotros.

FORMACIÓN Y TRANSFORMAGIÓN DE LOS BLOQUES DE PODER

Las Grandes Potencias tienen como objetivo instrumental la constitución de bloques de poder, los cuales son generalmente formalizados a través de tratados, pactos y alïanzas económicos, políticos y militares a fin de garantizar la consecución de los objetivos ulteriores de las Grandes Potencias o sea expandir sus zonas de influencia.

- Las fuerzas integradoras más generales que inducen a las grandes potencias y a los países que están en sus respectivas zonas de influencia a formar bloques son:

a. Estar en condiciones de disuadir posibles agresiones externas. 
ESTUDIOS INTERNACIONALES

b. Grear las condiciones politicas para facilitar el peculiar desarrollo económico de la unidad formada por las grandes potencias y sus zonas de influencia.

Como se mencionó anteriormente, nuestro interés de investigáción está centrado en el período posterior a la Segunda Guerra Mundial. No obstante, será necesario hacer una breve referencia al periodo entre las dos guerras, a fin de comprender mejor la formación y posterior desarrollo de los bloques capitalista y socialista.

FORMAGIÓN Y DESARROLLO DEL BLOQUE IMIPERIALISTA

Entre los factores que provocaron la Segunda Guerra MSundial debemos mencionar, por su importancia, los siguientes:

(i) Las contradicciones económicas inter-imperialistas que se habían acentuado rápidamente en el período posterior a la Primerá Guerra Mundial. Concretamente, las aspiraciones colonialistas de Italia en Abisinia; de Japón en China y de la para ese entonces recuperada Alemania en Austria, representaban una seria amenaza para Inglaterra, Francia y Estados Unidos.

(ii) El orden político impuesto en la $\mathrm{Paz}$ de Versalles había dejado un fondo de resentimiento en las antiguas zonas germanas, austro-húngara e inclusive rusa. El objetivo general que se perseguía con la $\mathrm{Paz}$ de Versalles era el de expandir las zonas de influencia de Inglaterra y Francia en áreas que tradicionalmente habían sido de influencia germana, austro-húngara y rusa. Para lograr este objetivo se utilizaron dos medios principales: (l) desmembrar el imperio austro-húngaro para crear nuevos estados, aprovechando los seculares conflictos de nacionalidades (eslavos, magiares, germanos y otras minorias). Esto, supuestamente serviria de freno a las posibles aspiraciones expansionistas alemanas. (2) Crear un "cinturón sanitario" que impidiera la expansión del socialismo (barrera integrada por algunos países balcánicos, Polonia, Turquía, Finlandia y las naciones bálticas).

- Sin embargo, las sucesivas invasiones de Austria, Checoslovaquia y Polonia por parte de Alemania y la firma en 1939 del tratado de no agresión germano-xuso modificó cualitativamente la correlación de fuerzas con Francia e Inglaterra por lo que estalló abiertamente la Segunda Guerra Mundial cuyo carácter dominante era el de una guerra inter-imperialista.

(iii) Los conflictos inter-imperialistas de la entreguerra expresaban en gran medida los efectos de la creciente crisis del campo 
capitalista y los efectos depauperantes que esta crisis había generado en los sectores medios, así como el ascenso combativo de las masas obreras. En Italia con el fascismo y en Alemania con el nazismo se dio una respuesta ideológica que permitió aglutinar internamente a la burguesía y a los sectores medios. Sin embargo, esta nueva ideología era contradictoria con el liberalismo burgués y a pesar de que era radicalmente opuesta al socialismo, de todos modos significó una división ideológica del campo capitalista. Con el ascenso al poder del fascismo y el nazismo y dadas sus aspiraciones colonialistas, esta división ideológica se transformó en antagónica.

(iv) El rápido desarrollo de la URSS pronto modificó el equilibrio europeo de la entreguerra, constituyéndose así en un grave peligro potencial; sobre todo en vista a las amenazas internas provenientes del ascenso del movimiento obrero en los países capitalistas.

El carácter inter-imperialista del conflicto en gestación y el manifiesto antagonismo del campo capitalista hacia la Unión Soviética determinó que este país, a la vez que trabajaba a marcha forzada preparándose para una virtual agresión, procurara mantenerse fuera del conflicto. Así, por una parte, la URSS en 1934 lleva a cabo pactos secretos de orden militar con el gobierno alemán. Ello le permitía elevar el nivel de efectividad de sus fuerzas armadas, mientras que a Alemania le daba la oportunidad de burlar las limitaciones militares impuestas a raíz de la Paz de Versalles. Más adelante, en 1939, la URSS firma un pacto de no agresión con Alemania a fin de no verse inmediatamente comprometida en una guerra que era inter-imperialista; Alemania, en cambio, se garantizaba la no apertura de un segundo frente. No obstante, la invasión alemana envuelve activamente a la URSS en el conflicto y en vista de la magnitud de la amenaza que significaba el nazismo, se produce la gran alianza entre Estados Unidos, Erancia, Inglaterxa y la Unión Soviética. A partir de ese momento, la guerra dejó de ser un puro conflicto inter-imperialista y en su desarrollo se gestó el nuevo orden mundial. Así al término de la Guerra emergen, por una parte, la Unión Soviética con una zona de influencia bien definida, integrada por Polonia, Rumania, Bulgaria, Checoslovaquia, Hungria, Albania, Yugoslavia y Alemania Oriental y por la otra Estados Unidos con el campo capitalista como zona de influencia. La formación y desarrollo del bloque soviético lo examinaremos más adelante. Por ahora concentraremos nuestra atención sobre el proceso en el campo capitalista.

Después de la Guerra, Estados Unidos emerge como un poder hegemónico absoluto en el campo capitalista. In este fenómeno influyeron en forma determinante los siguientes hechos: (a) Es- 
tados Unidos fue la única potencia que, debido a razones geopoliticas, estuvo fuera de la zona de combate y por tanto, en términos relativos, sus pérdidas materiales y humanas fueron pequeñas. En cambio, la economía de guerra provocó un enorme estímulo para el desarrollo industrial $y$, en general, el crecimiento del producto temitorial bruto; así, pues, las empresas norteamericanas rápidamente asimilaron y reafirmaron la supremacía tecnológica y pronto estuvieron en condiciones de ejercer un papel preponderante en el campo capitalista. (b) Los países europeos y Japón, en cambio, habían quedado devastados por la guerra y por tanto necesitaban desesperadamente de la ayuda norteamericana para poder reconstruir sus economías. A estas necesidades europeas y japonesas se sumaban las necesidades propias de expansión internacional inherentes al capitalismo norteamericano, cuyas corporaciones industriales y financieras requerían de nuevas oportunidades de inversión para seguir manteniendo su tasa de beneficios. En suma, pues, la burguesía norteamericana para mantener su hegemonía necesitaba del fortalecimiento de la burguesía europea y del desarrollo de la burguesía en el Japón. Esto fue comprendido aun durante el mismo curso de la guerra cuando el Congreso Norteamericano dictó la Ley de Préstamos y Arriendos en 1941, que permitió que entre marzo de 1941 y octubre de 1945 fluyera una ayuda hacia Europa de aproximadamente 48.000 millones de dólares. Luego, en 1943, se creó la UNRRA que fue la primera organización internacional de ayuda económica a los pueblos liberados. Sin embargo, después de las primeras manifestaciones de la Guerra Fría, especialmente después del estallido de la guerra civil en Grecia, la necesidad política de reconstrucción del campo capitalista y de formación de un bloque imperialista se hizo más evidente. Así, se ideó el Plan Marshall en 1947, el cual contemplaba ayuda económica y militar a los países devastados por la guerra que estuvieran fuera del campo socialista. (c) Otra fuerza integradora del bloque capitalista era la creciente amenaza del bloque socialista que estaba en expansión. No sólo porque al captar nuevas zonas para el socialismo restringía mercados y fuentes de materias primas al campo capitalista, sino también por los evidentes progresos militares que estaba experimentando la Unión Soviética. Esta potencial amenaza a la creación de fuerzas militares multinacionales y a la constitución de una complicada red de pactos- y alianzas los podemos clasificar atendiendo a sus objetivos específicos:

i. Pactos y alianzas dirigidos a fortalecer el aparato militar del bloque capitalista, adecuándolo para un choque frontal y 
total con el bloque socialista. El principal de estos pactos es la OTAN (Organización del Atlántico Norte).

ii. Pactos y Alianzas concebidos para servir de barrera a la expansión periférica del bloque socialista, especialmente en el continente asiático. Están orientados a crear capacidades para combatir tanto la guerra convencional como la subversiva. Esta clase de alianzas están tipificadas por la SEATO (Tratado de Asia Sud-oriental) y la CENTO (Organización del Tratado Central) .

iii. Alianzas orientadas a mantener la hegemonía política del bloque capitalista en la parte más segura de sus zonas periféricas. Militarmente están dirigidas a fortalecer las fuerzas nativas aliadas y en caso extremo, a apoyarlas con fuerzas de intervención. Este tipo de pacto es tipificado por la red de pactos bilaterales que ha sostenido los Estados Unidos con los diversos países latinoamericanos y que se hallan coordinados por la Junta Interamericana de Defensa.

(d) Una cuarta fuerza integradora del bloque capitalista bajo la hegemonía norteamericana la proveyó la progresiva decadencia de los antiguos imperios europeos. En efecto, el auge de los movimientos anticolonialistas, que aprovecharon el debilitamiento europeo de la post-guerra, cuadraba con la vieja política norteamericana del "open door", que buscaba establecer el "libre comercio" en las zonas reservadas a los paises europeos. En el periodo posterior a la guerra esta política, fue intensificada con miras a captar nuevos mercados para sus empresas y expandir su zona de influencia, manteniendo el carácter dependiente de las economías de los países periféricos. Al mismo tiempo, ello garantizaba que se impidiera su posible inclusión en el campo socialista.

(e) El debilitamiento de los vínculos coloniales europeos y el progresivo desplazamiento de su influencia económica por parte de los Estados Unidos, incrementó la necesidad europea de formar un mercado común. No obstante, la capaciclad de las empresas norteamericanas para capturar estas nuevas oportunidades a través de la formación de las empresas multinacionales, permitió que un movimiento aparentemente opositor a la hegemonía norteamericana, fuera transformado en una oportunidad más para incrementar la interdependencia del bloque capitalista.

Al mismo tiempo, sin embargo, las restricciones políticas impuestas a las empresas norteamericanas para comerciar con el campo. socialista en ciextos renglones considerados estratégicos, permitió el desarrollo de determinadas ramas industriales en los países europeos, especialmente en Alemania Occidental y en Japón. El resultado de 
todo ello fue Ia progresiva péidida del absolutismo de la hegemonía norteamericana y el surgimiento de tensiones y fuerzas desintegradoras dentro del bloque capitalista, sobre todo en la medida en que los países europeos, particularmente Alemania y Japón, avanzaban en su propio desarrollo industrial y tecinológico.

En suma pues, se trata de un desarrollo complejo y contradictorio en el cual las fuerzas integradoras, a partir de un cierto momento, pueden operar como desintegradoras del bloque. Así, estä en el interés de la burguesía norteamericana el desarrollo de sus zonas de equilibrio, pues el poder del bloque, frente a la amenaza socialista, está en el poder de todo el conjunto y no solamente en el de la gran potencia. Pero en la medida en que las burguesías de los países que forman las zonas de equilibrio adquieren poder, se pierde paulatinamente el carácter absoluto de la hegemonía de la gran potencia norteamericana. Ello da lugar al resurgimiento de sentimientos nacionalistas y de mayor autonomía en las zonas de equilibrio, lo que las impulsa a aprovechar todas las oportunidades de expansión económica, incluyendo las que ofrecen el intercambio con los paises socialistas. En toda esta dinámica, Ios páises periféricos juegan un papel igualmente importante, en el sentido clásico de ser fuentes de materias primas, proveer mercados para la industria y oportunidades de inversión para los excedentes de capitales, todo lo cual permite mantener altas las tasas de beneficio tanto en las zonas de equilibrio como en la gran potencia. El tipo de relación que se establece tiene, sin embargo, dos características bien definidas: (i) se mantiene el carácter clependiente de las economías de los países periféricos, en lo cual juega un papel muy importante el intercambio desigual y la superexplotación de la mano de obra y (ii) se previene políticamente que los paises que forman la zona de equilibrio reocupen sus antiguas colonias o formen nuevas. Así, el intento de Francia y Gran Bretaña, en combinación con Israel, de reivindicar su poder en el Medio Oriente fue en gran parte frustrado por el rechazo de la URSS y de Estados Unidos, lo que las hizo acatar la resolución de la ONU de evacuar Ios territorios ocupados.

(f) Finalmente, debemos mencionar otro factor integrador del bloque que es el monopolio del poderio atómico con fines militares. Los gastos de investigación; desarrollo y producción de una fuerza nuclear capaz de dar autonomía de enfrentamiento frente al poderío socialista, sólo puede afrontarlo la gran potencia capitalista, lo cual no solamente refuerza su hegemonía en el campo militar, sino que al mismo tiempo se constituye en una fuente de dinamismo para la economía norteamericana. En especial nos interesa mencionar aquí que en la situación actual el poderío atómico es un factor decisivo en el comportamiento de gran potencia, ya que 
solamente el riesgo de aniquilación de la humanidad mediante una guerra atómica es lo que puede refrenar a una gran potencia de tratar de capturar un país perteneciente a la zona de equilibrio de otra gran potencia.

DESARROLLO DEL BIOQUE SOCIALISTA.

En los párrafos anteriores se han hecho algunas referencias a la formación del bloque socialista, no obstante conviene precisar sus características más resaltantes. Quizás el hecho más preponderante de este proceso es que la Unión Soviética se vio precisada a adoptar un comportamiento de gran potencia aun cuando no estaban maduras todas las condiciones que permitían dicho comportamiento. Las razones de este fenómeno debemos encontrarlas tanto en la forma peculiar como se desarrolló el socialismo en la URSS como en la situación internacional.

Como es de dominio común, en el momento de la revolución socialista la Unión Soviética era un país en el cual el capitalismo había alcanzado un escaso nivel de desarrollo y su estructura socioeconómica era bastante heterogénea. En consecuencia, los objetivos de la sociedad socialista, formulados por Marx en el Programa de Gotha, tuvieron que ser pospuestos por el supuestamente objetivoinstrumental del clesarrollo forzado de las fuerzas productivas. Durante las tres primeras décadas se implantó un sistema de acumulación forzada y la ética productivista permeó todos los niveles de la conducta social. Un esfuerzo de esa naturaleza requirió la eliminación de la democracia inicial de los soviets y la implantación de un sistema burocrático y de planificación rígidamente centralizados. André Gorz ha caracterizado este tipo de clesarrollo de una manera bastante feliz: el socialismo difícil.

Es en este contexto que mejor puede apreciarse el significado de la permanente amenaza proveniente del campo capitalista, que mantuvo en continuo jaque a la URSS durante sus primeras décadas de existencia. Ello se vio agravado por el fracaso de la internalización de la revolución. En efecto, con la destrucción del grupo espartaquista se destruyó las esperanzas de la revolución en Alemania y el fracaso de Béla Kun en Hungria terminó por barrer el resto de las esperanzas.

De estas realidades emergió la perentoria necesidad de fortalecer el estado para construir el "socialismo en un solo pais". Así, las políticas seguidas durante los primeros años de la revolución estuvieron casi exclusivamente dirigidas a hacer nacer una economía autosu- 
ficiente y un estado fuerte y autónomo. Dentro de esta concepción jugó un papel importante el rápido desarrollo de la industria bélica; necesidad que se hizo más patente en los años inmediatamente posteriores a la Primera Guerra Mundial. La política internacional, en esta primera fase del socialismo en un solo país, estuvo dirigida a lograr un sistema de alianzas que neutralizara la posible agresión y mantuviera a la URSS fuera de los conflictos inter-imperialistas. Ya hemos mencionado que este es el sentido de los pactos militares secretos con Alemania y el pacto de no agresión firmado en 1939.

Pero la política de la Unión Soviética no se quedó alli. Siendo un movimiento ideológico que estaba históricamente en ascenso, se pensó entonces en la utilización de los Partidos Comunistas nacionales, quienes actuaron como gérmenes de potenciales zonas de influencia. La Tercera Internacional fue el instrumento utilizado para lograr estos objetivos. Esta influencia potencial se convierte en real después de la Segunda Guerra Mundial, cuando las organizaciones que estaban desde antes supeditadas a la política de la Unión Soviética, toman el poder en los países de Europa Central. Esta segunda fase, de consolidación del bloque socialista, se lleva a cabo bajo las tensiones de la Guerra Fría que, una vez más, hicieron definir el futuro del socialismo en base a los intereses soviéticos. El caso más importante es el de las presiones que se ejerció sobre el Partido Chino previamente a la revolución.

El sistema de pactos y alianzas que dieron lugar a la formación del bloque soviético fue consolidado por la amenaza del uso de la fuerza y a veces por la fuerza misma, cuando se consideraba: que el aliado no marchaba de acuerdo con los intereses de la Unión Soviética, los cuales eran ideológicamente identificados con los intereses del socialismo. Los primeros antecedentes están en el problema surgido con Ucrania, lo que dio lugar a que la teoría de la autodeterminación de las naciones quedara sujeta a la consideración del "interés del proletariado y del socialismo".

Posteriormente, en la fase de coexistencia pacífica, se dan un conjunto de factores de gran complejidad que terminan por crear fisuras dentro del bloque socialista.'Este fenómeno aún no ha sido bien estudiado por nosotros, sin embargo nuestra hipótesis muy preliminar es que el propio desarrollo interno de la URSS indujo la necesidad de cambiar substancialmente los supuestos básicos de la racionalidad del socialismo difícil. Por una parte, la acumulación forzada, la ética productivista, la planificación centralizada y la separación del partido, la burocracia y los sindicatos. A pesar de que en el período de Kruschev se dieron pasos importantes en este sentido, la estructura de poder creada en los años anteriores se resistió a ceder sus privilegios. Algunos autores, como los polacos Kuron 
y Modzelwski, argumentan que la burocracia se transformó en una auténtica clase dominante, con sus intereses propios y su conducta como tal, puesto que se trata de un sector que se apropia para sí parte del excedente generado por los trabajadores (privilegios y el mantenimiento de un aparato represivo de seguridad interna). Por la otra, el nivel de desarrollo alcanzado por los países integrantes del bloque, frente a la nueva situación, los hizo aspirar a mayores niveles de autonomía en la formulación y conducción de su política; estas aspiraciones se hacian particularmente legítimas dada la constatación de la consolidación del socialismo a nivel mundial y la disminución de la amenaza externa con la coexistencia pacífica. Sin embargo, los recientes acontecimientos ocurridos en Checoslovaquia revelan que la Unión Soviética está aún dispuesta a mantener su hegemonía absoluta en los países que forman parte de su zona de equilibrio. El caso de la escisión Ghino-Soviética es de particular interés puesto que representa el surgimiento de una posible gran potencia adicional dentro del campo socialista. No cabe dudas, de que ello ha modificado el panorama internacional y aun la naturaleza de las relaciones entre el campo capitalista y el socialista. Queda para ulterior estudio la consideración detallada de este problema.

ALGUNAS GENERALIZAGIONES SOBRE LA POLÍTICA DE LAS GRANDES POTENCIAS

A la luz de los análisis anteriores pueden extraerse algunas consideraciones de carácter teórico sobre la dinámica política de las grandes potencias:

1. El fortalecimiento y consolidación de un bloque, sólo es posible si además del permanente desarrollo de la Gran Potencia ocurre tạmbién un desarrollo substancial de algunos países de su zona de influencia. Los países en los cuales las Grandes Potencias tienen mayor interés en desarrollar son aquellos que por su previo potencial económico y por su ubicación geopolítica son considerados esenciales para el bloqueo en su conjunto. Estos son los países que llegan a formar la zona de equilibrio. El tipo de relaciones económicas que se establece entre la Gran Potencia y los paises pertenecientes a las zonas de equilibrio es el de interdependencia ligeramente asimétrica en favor de la Gran Potencia.

2. El progresivo fortalecimiento de los países que constituyen una 
zona de equilibrio tiende a intensificar la competencia intrabloque y a hacer surgir fuertes sentimientos nacionalistas. En el caso del bloque capitalista, esta competencia se manifiesta en las contradicciones inter-imperialistas. La competencia intrasocialista, en cambio, se da por la contradicción entre las demandas de los países que constituyen la zona de equilibrio, encaminadas a realizar el objetivo socialista de la igualdad económico-social de las naciones y las necesidades intrínsecas de la Gran Potencia de mantener su hegemonía política, militar $y^{i}$ económica en vista del conflicto potencial con el campo capitalista.

En ambos campos, sin embargo, la competencia se expresa en términos de la lucha de las respectivas zonas de equilibrio para desempeñar un papel cada vez más importante en la división del trabajo en el bloque, y en la lucha por obtener mayor influencia en las zonas periféricas.

3. La resultante de la competencia intra-bloque es doble. Por una parte, los paises del bloque encuentran ventajas en el comercio e intercambio científico, tecnológico y cultural con países semejantes de otros bloques. Por la otra, dentro de cada bloque se tiende a establecer una jerarquía que afecta desigualmente el intercambio entre los países del bloque. Esa jerarquía tiende a ser, en orden de dominación: Gran Potencia - Zona de Equilibrio - Zona Periférica.

En el caso del bloque capitalista el fenómeno se manifiesta concretamente en (i) grados de dependencia económica y en particular de intercambio económico desigual y explotación de la mano de obra; (ii) niveles de dependencia científica y tecnológica; (iii) grados de dominación política y militar y (iv) modalidades de penetración y alienación cultural.

En el caso del bloque socialista las manifestaciones concretas han sido menos estudiadas, sin embargo, se pueden señalar las siguientes: (i) supeditación científica y tecnológica; (ii) dominación política y militar; (iii) asignación, mediante la planificación, de un papel específico en la división inter-socialista del trabajo y (iv) control ideológico y cultural. Naturalmente estas característicàs también se dan en diversos grados.

4. En suma, las zonas periféricas inevitablemente resultan jugando un papel secundario dentro del bloque y sometidas a los grados más intensos de dominación y control. Como se trata de países en donde generalmente existen profunclas contradicciones estructurales, especialmente en el caso de aquellos países que están en la zona de influencia capitalista, siempre hay presente un potencial de rebelión que aumenta con la difusión de la con- 
ciencia de que la autonomía es indispensable para neutralizar las relaciones de dominación y adquirir un desarrollo autónomo. Estas últimas consideraciones son históricamente aplicables al campo capitalista; en cambio, en las zonas periféricas socialistas aún no se encuentran bien definidas o bien consolidadas como para que hayan surgido fenómenos de este tipo.

5. La necesidad de expansión y de consolidación de las zonas de influencia de las grandes potencias trae como consecuencia su necesario enfrentamiento, pero la naturaleza de este enfrentamiento cambia según los siguientes factores:

a. Grado de cohesión de los bloques: A mayor cohesión de los bloques, mayor es la probabilidad de un enfrentamiento frontal de las grandes potencias, puesto que se reducen las posibilidades de intercambio entre pafses de los bloques y por tanto no se generan intereses mutuos que induzcan a la negociación, acuerdos parciales u otras formas de compromisos tácitos.

b. Grado de capacidad disuasiva de agresiones externas: En la actualidad se mide por el poderío atómico, el cual ha llegado ya en ambos campos a ser de tal capacidad destructiva que disminuyen las posibilidades de enfrentamiento total, puesto que ello prácticamente implicaría la desaparición de la civilización.

En consecuencia, las posibilidades de enfrentamiento en las zonas de equilibrio quedan también reducidas a un mínimo puesto que ello implicaría un enfrentamiento directo de las grandes potencias. Esta amenaza de guerra atómica deja como única posibilidad el enfrentamiento en las zonas periféricas, en donde las guerras serían de tipo convencional. Más aún, como se señaló anteriormente, las condiciones en las zonas periféricas capitalistas son tales que allí es donde tienden a estallar los conflictos, los cuales pueden ser luchas por el poder entre facciones de la clase dominante, pero de diferentes matices ideológicos y políticos, o guerras revolucionarias.

Sin embargo, no todo conflicto que estalle en una zona periférica tiende a convertirse en un enfrentamiento indirecto entre las grandes potencias. Ello depende principalmente de las posibilidades que tienen las grandes potencias de movilizar un apoyo logístico efectivo. En general, se puede decir que las zonas periféricas "calientes" (o sea aquellas en donde puede darse un enfrentamiento indirecto entre las grandes potencias), están geográficamente ubicadas en aquellas partes del globo donde se superponen las respectivas capacidades de eficiente movilización y apoyo militares.

En el momento actual se puede decir que los Estados Unidos tienen una capacidad de movilización tal que cubren enteramente 
al globo terráqueo; en cambio, la URSS sólo puede cubrir efectivamente desde Asia Oriental hasta el Medio Oriente y posiblemente Africa, por lo que estas son las zonas calientes de la actualidad.

No obstante, el rápido desarrollo que está experimentando en la actualidad la armada soviética y en especial dada su decisión de construir grandes portaviones, están rápidamente expandiendo su capacidad de movilización y junto con ello, quiéranlo o no, también las zonas calientes. En el caso de América Latina, con la consolidación del socialismo en Cuba y probablemente en Chile, la situación puede presentarse a un mediano plazo; de modo que para finales de esta década o comienzos de la próxima, quizá no será una utopía la proposición del Che Guevara de crear en América Latina uno, dos, muchos Vietnam. 